\title{
Os êxitos da história social do trabalho
}

\author{
Aldrin Castellucci* \\ Caio Castro Gerbelli** \\ David P. Lacerda*** \\ Melina K. Perussatto**** \\ Micaele Irene Scheer***** \\ Nauber Gavski da Silva******
}

C

oncebido originalmente em 1999 por docentes do Rio Grande do Sul e São Paulo em suas respectivas seções regionais e formalizado no ano 2000 no âmbito da Associação Nacional de História, o GT Mundos do Trabalho completa 20 anos de existência. O GTMT teve crescimento rápido, agregando mais de uma centena de membros oriundos de várias instituições e estados do Brasil, logo em seus primeiros anos de atividade. Desde que foi criado, o GT Mundos do Trabalho participou ativamente de todos os eventos bianuais estaduais e nacionais da ANPUH-Brasil. No caso dos Simpósios Nacionais da ANPUH, o GTMT organizou, desde 2001, entre dois e três simpósios temáticos, reunindo dezenas de professores universitários e pesquisadores em diferentes níveis de formação nas diversas universidades do Brasil.

Além disso, desde o início, o GT realizou seu próprio evento, que teve abrangência nacional nas Jornadas de História do Trabalho realizadas na UFPel (Pelotas, 2002), UFSC (Florianópolis, 2004), UFF (Niterói, 2006) e UNESC (Criciúma, 2008), assumindo caráter internacional nos Seminários Mundos do Trabalho sediados pela UFSC (Florianópolis, 2010),

* $\quad$ Editor-Chefe da Revista Mundos do Trabalho. Doutor em História Social pela Universidade Federal da Bahia (UFBA). Professor Titular Pleno da Universidade do Estado da Bahia (UNEB).

** Editor da Revista Mundos do Trabalho. Mestre em História pela Universidade Federal de São Paulo (Unifesp). Professor na Secretaria Municipal de Educação de Santo André.

*** Editor da Revista Mundos do Trabalho. Doutor em História Social pela Universidade Estadual de Campinas (Unicamp), com período de estágio sanduíche em King's College London, Universidade de Londres.

**** Editora da Revista Mundos do Trabalho. Doutora em História pela Universidade Federal do Rio Grande do Sul (UFRGS). Professora Adjunta da Universidade Federal do Rio Grande do Sul (UFRGS).

***** Editora da Revista Mundos do Trabalho. Doutora em História pela Universidade Federal do Rio Grande do Sul (UFRGS).

****** Editor da Revista Mundos do Trabalho. Doutor em História pela Universidade Federal do Rio Grande do Sul (UFRGS). 
Aldrin Castellucci, Caio Castro Gerbelli, David P. Lacerda, Melina K. Perussatto, Micaele Irene Scheer e Nauber Gavski da Silva

FGV (Rio de Janeiro, 2012), UNEB (Salvador, 2014), UFAM (Manaus, 2016) e UFRGS (Porto Alegre, 2018). Em 2020 o evento seria realizado na UFRRJ, mas teve que ser feito no formato webinário em função da pandemia da covid-19. Ao longo desses anos, centenas de acadêmicos do Brasil e do exterior apresentaram suas pesquisas nos Seminários Internacionais Mundos do Trabalho, feitos em anos alternados com os da ANPUH-Brasil.

O GTMT também colheu excelentes frutos com sua revista. Fundada em 2009, a Mundos do Trabalho publicou 20 números semestrais até 2018. Em 2019, quando fez seu aniversário de 10 anos, adotou o sistema de publicação contínua, no qual se publica um grande volume anual, implementou um novo projeto gráfico na capa e no miolo e envidou esforços para inserir a publicação em novos indexadores de metadados, buscadores e bibliotecas virtuais como forma de garantir maior inserção e impacto de seus artigos e autores. ${ }^{1}$

De fato, o volume 11 (2019) teve 14 artigos na seção livre, dois dossiês com outros 15 artigos e uma resenha. A seção livre de 2019 deu sequência aos esforços vigentes desde os primeiros números da revista para publicar artigos sobre as diferentes experiências de organização e luta dos trabalhadores em distintas épocas e lugares do mundo além-Brasil. Antonio Luigi Negro analisou a produção e circulação de imagens fotográficas em cartões postais durante o processo de reconciliação nacional estadunidense do pós-abolição para examinar de perto a questão das supremacias de raça e classe a partir da década de 1880. James Oakes examinou tanto o papel do Partido Republicano e do presidente Lincoln quanto a agência dos próprios escravos em sua adesão à União durante a Guerra Civil Americana. Marc Adam Hertzman investigou a relação entre suicídio, raça e trabalho forçado nas Américas. Deivison Gonçalves Amaral estudou as interações e transferências entre as organizações católicas para trabalhadores de Camaragibe (Brasil) e Val-des-Bois (França) entre a última década do século XIX e a primeira do século XX. Por fim, João Lázaro destacou o papel das batalhas internas da Associação Internacional dos Trabalhadores em Portugal entre 1871 e $1873 .^{2}$

Vale a pena mencionar alguns exemplos prévios acerca dessa preocupação da revista, como os artigos de Joana Dias Pereira sobre o sindicalismo revolucionário em Portugal, publicado em 2009; Rana Behal, a respeito do trabalho nas plantações de chá em Assam, Índia, sob o domínio colonial; e Lucien van der Walt, que tratou de anarquismo e sindicalismo revolucionário na África do Sul, ambos dados ao público em 2010. Em 2011, destaque-se

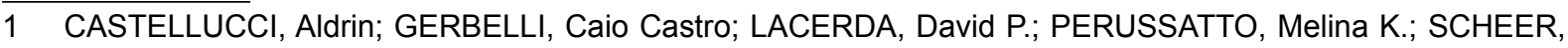
Micaele Irene; SILVA, Nauber Gavski da. Mundos do Trabalho: desafios e perspectivas. Mundos do Trabalho, Florianópolis, v. 11, p. 1-2, 2019.

2 NEGRO, Antonio Luigi. Black Americana. Supremacia racial e supremacia de classe em fotografias da virada do século XIX ao XX. Mundos do Trabalho, Florianópolis, v. 11, p. 1-31, 2019; OAKES, James. Não existem rebeldes negros: repensando o legado de E. P. Thompson para a Guerra Civil Americana. Mundos do Trabalho, Florianópolis, v. 11, p. 1-13, 2019; HERTZMAN, Marc Adam. Diferenças fatais: suicídio, raça e trabalho forçado nas Américas. Mundos do Trabalho, Florianópolis, v. 11, p. 1-38, 2019; AMARAL, Deivison Gonçalves. A corporação cristã em perspectiva transnacional: interações e transferências entre as organizações católicas para trabalhadores de Camaragibe (Brasil) e Val-des-Bois (França). Mundos do Trabalho, Florianópolis, v. 11, p. 1-23, 2019; LÁZARO, João. Associação Internacional dos Trabalhadores em Portugal (1871-1873). Mundos do Trabalho, Florianópolis, v. 11, p. 1-19, 2019. 
a publicação dos artigos de Rodolfo Porrini analisando a relação entre esquerda e cultura operária no Uruguai; Beatriz Mamigonian examinando o trabalho de africanos no Brasil e no Caribe britânico entre 1830 e 1850; e Céline Flory com uma pesquisa sobre a prática do "resgate", isto é, a alforria de escravos africanos e sua submissão ao trabalho nas plantations das Ilhas Reunião, da Guiana Francesa e das ilhas do Caribe francês no século XIX. Em 2012 Mundos do Trabalho publicou artigos de Schiavi Marcos sobre o processo de organização dos operários têxteis da fábrica argentina da Alpargatas em meados do século XX. De 2013 merecem destaque os artigos de Michel Ralle a respeito da relação do anarquismo com a cultura operária na Espanha entre 1868 e 1910; e Márcia C. de O. Cury sobre a mobilização dos trabalhadores do Chile sob o governo da Unidade Popular (1970-1973). Frank Meyer é um dos autores de 2014. Ele faz um estudo comparativo em perspectiva transnacional a respeito do impacto da produção de alumínio sobre as condições socioambientais e de trabalho nas comunidades de Porto Trombetas, localizada no estado do Pará, e Årdal, na Noruega. Finalmente, de 2017, é preciso mencionar o artigo de Rossana Barragán Romano sobre os k'ajchas, trabalhadores autônomos das minas de Potosí, na Bolívia, entre 1935 e $1940 .^{3}$

O primeiro dossiê do volume 11 (2019), "Trabalhadores e Segunda Guerra Mundial", organizado por Alexandre Fortes e Felipe Ribeiro, foi composto por uma apresentação e seis artigos de Edinaldo Antonio Oliveira Souza, Fernanda Lima Rabelo, Tassiane Mélo de Freitas, Patrícia Costa de Alcântara, Tamires Xavier Soares e Frederico Soares Ribeiro. ${ }^{4}$

3 PEREIRA, Joana Dias. Sindicalismo revolucionário em Portugal. Mundos do Trabalho, Florianópolis, v. 1, n. 2, p. 195-220, 2009; BEHAL, Rana P. Estrutura de poder, disciplina e trabalho nas plantações de chá em Assam, sob o domínio colonial. Mundos do Trabalho, Florianópolis, v. 2, n. 3, p. 12-46, 2010; WALT, Lucien van der. Negro e Vermelho: anarquismo, sindicalismo revolucionário e pessoas de cor na África Meridional nas décadas de 1880-1920. Mundos do Trabalho, Florianópolis, v. 2, n. 4, p. 174-217, 2010; PORRINI, Rodolfo. Izquierda uruguaya y culturas obreras. Propuestas al 'aire libre': pic-nics y paseos campestres en Montevideo, 1920-1950. Mundos do Trabalho, Florianópolis, v. 3, n. 6, p. 105-129, 2011; MAMIGONIAN, Beatriz. Em nome da liberdade: abolição do tráfico de escravos, o Direito e o ramo brasileiro do recrutamento de africanos (Brasil - Caribe Britânico, 1830-1850). Mundos do Trabalho, Florianópolis, v. 3, n. 6, p. 67-92, 2011; FLORY, Céline. Alforriar sem libertar: a prática do "resgate" de cativos africanos no espaço colonial francês no século XIX. Mundos do Trabalho, Florianópolis, v. 3, n. 6, p. 93-104, 2011; MARCOS, Schiavi. Organización y conflictividad textil: La Fábrica Argentina de Alpargatas a comienzos del primer gobierno peronista. Mundos do Trabalho, Florianópolis, v. 4, n. 8, p. 252-272, 2012; RALLE, Michel. Primer anarquismo español y cultura obrera (1868-1910). El peso de la subordinación a la defensa de la identidad obrera. Mundos do Trabalho, Florianópolis, v. 5, n. 9, p. 139-170, 2013. CURY, Márcia C. de O. Sindicatos e Cordões Industriais: uma reflexão em torno do histórico da organização operária chilena e da sua mobilização revolucionária. Mundos do Trabalho, Florianópolis, v. 5, n. 10, p. 221-247, 2013; MEYER, Frank. Cidades-empresa numa cadeia produtiva transnacional: dimensões sociais e ambientais da produção de alumínio em Porto Trombetas, Brasil, e Årdal, Noruega. Mundos do Trabalho, Florianópolis, v. 6, n. 11, p. 107-127, 2014; ROMANO, Rossana Barragán. Los k'ajchas* y los proyectos de industria y nación en Bolivia (1935-1940). Mundos do Trabalho, Florianópolis, v. 9, n. 18, p. 25-48, 2017.

4 FORTES, Alexandre; RIBEIRO, Felipe. Trabalhadores e Segunda Guerra Mundial: debates introdutórios para um dossiê. Mundos do Trabalho, Florianópolis, v. 11, p. 1-17, 2019; SOUZA, Edinaldo Antonio Oliveira. Trabalhadores, sindicatos e lutas por direitos na Bahia no final da Segunda Guerra Mundial. Mundos do Trabalho, Florianópolis, v. 11, p. 1-26, 2019; RABELO, Fernanda Lima. Na era da expertise: formação e qualificação dos servidores públicos durante a Segunda Guerra Mundial. Mundos do Trabalho, Florianópolis, v. 11, p. 1-21, 2019; FREITAS, Tassiane Mélo de. "Viva a classe operária mineira unida! Contra a guerra imperialista!": os mineiros de carvão do Rio Grande do Sul e o esforço de guerra (1942-1945). Mundos do Trabalho, Florianópolis, v. 11, p. 1-24, 2019; ALCÂNTARA, Patrícia Costa de. Limites e alcances da propaganda do Estado Novo para mobilização nacional durante a Segunda Guerra Mundial. Mundos do Trabalho, Florianópolis, v. 11, p. 1-23, 2019; SOARES, Tamires Xavier. A guerra no prato: uma breve análise sobre o problema de abastecimento de carne verde no Rio Grande do Sul, durante a Segunda 
Aldrin Castellucci, Caio Castro Gerbelli, David P. Lacerda, Melina K. Perussatto, Micaele Irene Scheer e Nauber Gavski da Silva

O segundo dossiê intitulou-se "Beatriz Ana Loner: mundos do trabalho e pós-abolição" e foi organizado por Fernanda Oliveira da Silva, Melina Kleinert Perussatto e Micaele Irene Scheer. Contou com uma apresentação e sete artigos de Paulo Luiz Crizel Koschier, Aristeu Elisandro Machado Lopes, Lorena Almeida Gill, Claudia Daiane Garcia Molet, Lúcia Helena Oliveira Silva e Regina Célia Lima Xavier, Paulo Roberto Staudt Moreira e Fernando Cauduro Pureza. ${ }^{5}$

Tendo publicado inúmeros artigos em espanhol desde o seu primeiro ano de existência, o volume de 2019 da Mundos do Trabalho também deu sequência ao investimento iniciado em 2018 no que diz respeito à publicação de textos originais em inglês com traduções para o português. ${ }^{6} \mathrm{~A}$ iniciativa atende aos objetivos de incrementar a inserção internacional da revista e ampliar seu número de leitores qualificados. Nesse caso, convém mencionar os artigos de Emile Chabal, sobre a participação de Eric Hobsbawm no Grupo de Historiadores do Partido Comunista da Grã-Bretanha no período de 1946 a 1956, e Pamela Cox, com uma colaboração sobre os desafios e vantagens de traduzir a pesquisa histórica acadêmica em formatos populares para a televisão e outra a respeito dos usos de fontes visuais na história do trabalho a partir de uma seleção de filmes protagonizados por trabalhadores britânicos do início do século XX, reunidos na série de história Edwardian Britain in Colour, do Canal 5 do Reino Unido. ${ }^{7}$

A Mundos do Trabalho de 2019 também trouxe artigos versando sobre temas clássicos da história do trabalho em âmbito nacional e internacional, a exemplo do mutualismo, sindicalismo e greves. Com relação ao associativismo de auxílio-mútuo, há o artigo de Celina Batalha Oliveira Lima sobre a Sociedade Bolsa de Caridade, uma entidade fundada em 1872, exclusiva dos trabalhadores do Arsenal de Guerra da Bahia, mas que depois se abriu a sócios

Guerra Mundial. Mundos do Trabalho, Florianópolis, v. 11, p. 1-14, 2019; RIBEIRO, Frederico Soares. Os Febianos: experiência, consciência e agência dos trabalhadores brasileiros convocados para a guerra na Força Expedicionária Brasileira - FEB (1943 - 1945). Mundos do Trabalho, Florianópolis, v. 11, p. 1-30, 2019.

5 SILVA, Fernanda Oliveira da; PERUSSATTO, Melina Kleinert; SCHEER, Micaele Irene. Apresentação do dossiê Beatriz Ana Loner: Mundos do Trabalho e Pós-Abolição. Mundos do Trabalho, Florianópolis, v. 11, p. 1-4, 2019; KOSCHIER, Paulo Luiz Crizel. Guia do Arquivo da Justiça do Trabalho de Pelotas. Núcleo de Documentação Histórica da UFPel - Professora Beatriz Loner. Mundos do Trabalho, Florianópolis, v. 11, p. 1-20, 2019; LOPES, Aristeu Elisandro Machado. Os trabalhadores negros em 3x4: fotografia, história do trabalho e pós-abolição. Pelotas-RS, 1933-1944. Mundos do Trabalho, Florianópolis, v. 11, p. 1-24, 2019; GILL, Lorena Almeida. Um ofício em transformação: a pesca artesanal contada por quem a pratica (Pelotas, RS). Mundos do Trabalho, Florianópolis, v. 11, p. 1-27, 2019; MOLET, Claudia Daiane Garcia. Chica Brincuda, "a última a ficar nestas terras de escravos": mulheres negras no Litoral Negro do Rio Grande do Sul. Mundos do Trabalho, Florianópolis, v. 11, p. 1-20, 2019; SILVA, Lúcia Helena Oliveira. Historicizando o associativismo negro: contribuições e caminhos da historiografia. Mundos do Trabalho, Florianópolis, v. 11, p. 1-15, 2019; MOREIRA, Paulo Roberto Staudt. Havemos de ser atendidos em nossos direitos, uma vez que servimos para votantes e soldados, não obstante a nossa cor: associativismo negro, direitos e cidadania (a Sociedade Beneficente Cultural Floresta Aurora, Porto Alegre, séc. XIX). Mundos do Trabalho, Florianópolis, v. 11, p. 1-30, 2019; PUREZA, Fernando Cauduro. Cruzando olhares: estabelecendo diálogos entre E. P. Thompson e Angela Davis. Mundos do Trabalho, Florianópolis, v. 11, p. 1-20, 2019.

6 Sobre essa questão, cf.: CASTELLUCCI, Aldrin; LACERDA, David P.; SILVA, Nauber Gavski da. Apresentação: Variedades de História do Trabalho. Mundos do Trabalho, Florianópolis, v. 10, n. 19, p. 9-13, 2018.

7 COX, Pamela. Translating Labor History for Television. Mundos do Trabalho, Florianópolis, v. 10, n. 19, p. $17-$ 30, 2018; CHABAL, Emile. Historians of the world unite! Eric Hobsbawm and the Communist Party Historians Group, 1946-1956. Mundos do Trabalho, Florianópolis, v. 10, n. 19, p. 71-82, 2018; COX, Pamela. The uses of film and visual sources in labour history. Mundos do Trabalho, Florianópolis, v. 11, p. 1-12, 2019. 
de fora daquela instituição. ${ }^{8} \mathrm{O}$ mutualismo entre os trabalhadores foi um importante objeto de pesquisa da Mundos do Trabalho desde o início, merecendo um dossiê organizado por Marcelo Mac Cord e Osvaldo Batista Acioly Maciel em 2010 e contando com artigos de Claudio H. M. Batalha, Claudia Maria Ribeiro Viscardi, Aldrin A. S. Castellucci, Adhemar Lourenço da Silva Jr., Marcelo Mac Cord, Ronaldo Pereira de Jesus e David Patrício Lacerda, e Paula Christina Bin Nomelini. ${ }^{9}$ Em 2012 a revista publicou também um artigo de Rafaela Leuchtenberger sobre o tema. ${ }^{10}$

Sindicalismo e greves continuam temas centrais para a história do trabalho e foram revisitados por Philipe Murillo Santana de Carvalho em artigo sobre a paralisação dos ferroviários nas cidades de Ilhéus e Itabuna, no sul da Bahia, em maio de 1927. ${ }^{11}$ Antes de 2019, vários autores se debruçaram sobre essa dimensão do movimento operário e sindical e suas relações com a política e o Estado em diversos números da Mundos do Trabalho, a exemplo de Murilo Leal Pereira Neto em 2009, César Augusto Bubolz Queirós em 2009 e 2013, Fernando Cauduro Pureza em 2010, Francisco Barbosa de Macedo em 2011, Lucas Poy em 2012, Sidney da Silva Lobato em 2015 e Dmitri van den Bersselaar e Frederico Duarte Bartz em 2016. ${ }^{12}$

$8 \quad$ LIMA, Celina Batalha Oliveira. Do Arsenal de Guerra para o mundo operário mais amplo: estudo centrado na Sociedade Bolsa de Caridade (1872-1930). Mundos do Trabalho, Florianópolis, v. 11, p. 1-29, 2019.

9 MAC CORD, Marcelo; MACIEL, Osvaldo Batista Acioly. Apresentação. Os trabalhadores e o mutualismo. Mundos do Trabalho, Florianópolis, v. 2, n. 4, p. 1-11, 2010; BATALHA, Claudio H. M. Relançando o debate sobre o mutualismo no Brasil: as relações entre corporações, irmandades, sociedades mutualistas de trabalhadores e sindicatos à luz da produção recente. Mundos do Trabalho, Florianópolis, v. 2, n. 4, p. 12-22, 2010; VISCARDI, Claudia Maria Ribeiro. O estudo do mutualismo: algumas considerações historiográficas e metodológicas. Mundos do Trabalho, Florianópolis, v. 2, n. 4, p. 23-39, 2010; CASTELLUCCI, Aldrin A. S. A luta contra a adversidade: notas de pesquisa sobre o mutualismo na Bahia (1832-1930). Mundos do Trabalho, Florianópolis, v. 2, n. 4, p. 40-77, 2010; SILVA JR., Adhemar Lourenço da. Oligarquias em sociedades de socorros mútuos (1854-1940). Mundos do Trabalho, Florianópolis, v. 2, n. 4, p. 78-108, 2010; MAC CORD, Marcelo. Redes de sociabilidade e política: mestres de obras e associativismo no Recife oitocentista. Mundos do Trabalho, Florianópolis, v. 2, n. 4, p. 109-125, 2010; JESUS, Ronaldo Pereira de; LACERDA, David Patrício. Dinâmica associativa no século XIX: socorro mútuo e solidariedade entre livres e libertos no Rio de Janeiro imperial. Mundos do Trabalho, Florianópolis, v. 2, n. 4, p. 126-142, 2010; NOMELINI, Paula Christina Bin. Mutualismo em Campinas no início do século XX: possibilidades para o estudo dos trabalhadores. Mundos do Trabalho, Florianópolis, v. 2, n. 4, p. 143-173, 2010.

10 LEUCHTENBERGER, Rafaela. A organização e a atividade das associações voluntárias de socorro mútuo de trabalhadores de Florianópolis - SC (1886-1932). Mundos do Trabalho, Florianópolis, v. 4, n. 7, p. 57-84, 2012.

11 CARVALHO, Philipe Murillo Santana de. Na defesa dos sagrados interesses: a greve dos ferroviários no sul da Bahia (Ilhéus e Itabuna, maio de 1927). Mundos do Trabalho, Florianópolis, v. 11, p. 1-26, 2019.

12 PEREIRA NETO, Murilo Leal. A fábrica, o sindicato, o bairro e a política: a "reinvenção" da classe trabalhadora de São Paulo (1951-1964). Mundos do Trabalho, Florianópolis, v. 1, n. 1, p. 225-257, 2009; QUEIRÓS, César Augusto Bubolz. A Questão Social no Rio Grande do Sul: Positivismo, Borgismo e a incorporação do proletariado à sociedade moderna. Mundos do Trabalho, Florianópolis, v. 1, n. 1, p. 97-124, 2009; PUREZA, Fernando Cauduro. "Os bondes já estão parando": uma reflexão sobre as greves de abril de 1945 em Porto Alegre. Mundos do Trabalho, Florianópolis, v. 2, n. 3, p. 236-260, 2010; MACEDO, Francisco Barbosa de. A greve de 1980: redes sociais e espaço urbano na mobilização coletiva dos metalúrgicos de São Bernardo do Campo. Mundos do Trabalho, Florianópolis, v. 3, n. 5, p. 136-165, 2011; POY, Lucas. Las primeras huelgas de la construcción y los inicios de la lucha por la reducción de la jornada laboral en Buenos Aires (1893-1895). Mundos do Trabalho, Florianópolis, v. 4, n. 7, p. 198-217, 2012; QUEIRÓS, César Augusto Bubolz. A ação coletiva da classe patronal de Porto Alegre nas grandes greves da Primeira República (1917-1919). Mundos do Trabalho, Florianópolis, v. 5, n. 9, p. 215-237, 2013; LOBATO, Sidney da Silva. Movimentos sociais contra autoritarismos locais e inseguranças estruturais: as lutas de partidos, associações e sindicatos amapaenses, entre 1944 e 1964. Mundos do Trabalho, Florianópolis, v. 7, n. 13, p. 233-253, 2015; BERSSELAAR, Dmitri van den. "Não adianta insultar os patrões": sindicatos, nacionalismo e o ambiente de trabalho em Gana, 1950-1987. Mundos do Trabalho, Florianópolis, v. 8, n. 16, p. 95-105, 2016; BARTZ, Frederico Duarte. Liga de Defesa Popular: a construção de um espaço de luta política entre os trabalhadores organizados de Porto 
Aldrin Castellucci, Caio Castro Gerbelli, David P. Lacerda, Melina K. Perussatto, Micaele Irene Scheer e Nauber Gavski da Silva

A condição operária, os processos de trabalho, o disciplinamento dos trabalhadores e as diversas formas de resistência operária também são temas tratados pela revista. Nesse caso, cabe citar os artigos de Evangelia Aravanis, em 2010 e Ana Beatriz Ribeiro Barros Silva e Maria Elisa Lemos Nunes da Silva, em 2015, além do dossiê "Os mineiros e o trabalho em mineração", organizado, também em 2015, por Clarice Gontarski Speranza, no qual podem ser encontrados artigos de Ad Knotter, Rafael de Freitas e Souza, Felipe Figueiró Klovan, Marta Cioccari e Carlos Renato Carola e Giovani Felipe. ${ }^{13}$

Desde o início, Mundos do Trabalho sempre esteve atenta aos debates e inovações no interior da história social do trabalho. De olho nas relações entre classe e gênero, a revista ofereceu a seus leitores, ainda em 2009, um dossiê organizado por Fabiane Popinigis e Cristiana Schettini sobre o tema, contando com contribuições de Daniela Sbravati, Valeria Pita, Lerice de Castro Garzoni, Silvana Alejandra Palermo, Andrea Andújar e Chitra Joshi. ${ }^{14}$

As complexas relações entre classe, gênero, etnicidade, racismo e antirracismo também foram examinados nas pesquisas sobre trabalho doméstico publicadas na Mundos do Trabalho por Maciel Henrique Carneiro da Silva, em 2011 e Flavia Fernandes de Souza, em 2015. ${ }^{15} \mathrm{Em}$ 2018, esses autores foram convidados para organizar um dossiê sobre o tema, no qual foram publicados artigos de Paolo Passaniti, Madeleine Octavia Roberts, Juliana Sousa, Marina

Alegre após a Greve de 1917. Mundos do Trabalho, Florianópolis, v. 8, n. 16, p. 117-130, 2016.

13 ARAVANIS, Evangelia. A industrialização no Rio Grande do Sul nas primeiras décadas da República: a organização da produção e as condições de trabalho (1889-1920). Mundos do Trabalho, Florianópolis, v. 2, n. 3, p. 148-180, 2010; SILVA, Maria Elisa Lemos. Entre lançadeiras, guindastes e trilhos: doenças e acidentes de trabalho em Salvador nas décadas de 1930 e 1940. Mundos do Trabalho, Florianópolis, v. 7, n. 13, p. 215231, 2015; SILVA, Ana Beatriz Ribeiro Barros. "Brasil, o 'campeão mundial de acidentes de trabalho'”: controle social, exploração e prevencionismo durante a ditadura empresarial-militar brasileira. Mundos do Trabalho, Florianópolis, v. 7, n. 13, p. 151-173, 2015; SPERANZA, Clarice Gontarski. Apresentação. Os mineiros e o trabalho em mineração: experiências, lutas e identidades. Mundos do Trabalho, Florianópolis, v. 7, n. 14, p. 5-9, 2015; KNOTTER. Ad. Mineração de carvão, migração e etnicidade: uma história global. Mundos do Trabalho, Florianópolis, v. 7, n. 14, p. 13-35, 2015; SOUZA, Rafael de Freitas e. A efêmera e fatal mina de Cata Branca: mineração e trabalho numa companhia aurífera inglesa em Minas Gerais (1832-1844). Mundos do Trabalho, Florianópolis, v. 7, n. 14, p. 37-52, 2015; KLOVAN, Felipe Figueiró. Quebrando a calma: a mobilização dos mineiros de carvão do Rio Grande do Sul pelo cumprimento das leis trabalhistas durante o governo provisório de Getúlio Vargas (1930-1934). Mundos do Trabalho, Florianópolis, v. 7, n. 14, p. 53-74, 2015; CIOCCARI, Marta. Entre o campo e a mina: valores e hibridações nas trajetórias de mineiros de carvão no sul do Brasil. Mundos do Trabalho, Florianópolis, v. 7, n. 14, p. 75-98, 2015; CAROLA, Carlos Renato; FELIPE, Giovani. A "banalidade do mal" socioambiental na história da indústria carbonífera catarinense: acidentes, sofrimentos e mortes na segunda metade do século XX. Mundos do Trabalho, Florianópolis, v. 7 , n. 14, p. 99-123, 2015.

14 POPINIGIS, Fabiane; SCHETTINI, Cristiana. Apresentação. Perspectivas de gênero nos mundos do trabalho. Mundos do Trabalho, Florianópolis, v. 1, n. 2, p. 5-12, 2009; SBRAVATI. Daniela. Mulheres de (in)certa condição. Mundos do Trabalho, Florianópolis, v. 1, n. 2, p. 13-40, 2009; PITA, Valeria. Nos termos de suas benfeitoras: encontros entre trabalhadoras e as senhoras da sociedade de beneficência, Buenos Aires, 1852-1870. Mundos do Trabalho, Florianópolis, v. 1, n. 2, p. 41-64, 2009; GARZONI, Lerice de Castro. Nas fronteiras do não-trabalho: trabalhadoras pobres e as definições de vadiagem no início do século XX. Mundos do Trabalho, Florianópolis, v. 1, n. 2, p. 65-93, 2009; PALERMO, Silvana Alejandra. Masculinidade, conflitos e solidariedades no mundo do trabalho ferroviário na Argentina (1912-1917). Mundos do Trabalho, Florianópolis, v. 1, n. 2, p. 94-123, 2009; ANDÚJAR, Andrea. Bloqueando estradas, construindo pontes: as mulheres piqueteiras em Salta, Argentina. Mundos do Trabalho, Florianópolis, v. 1, n. 2, p. 124-146, 2009; JOSHI, Chitra. Além da polêmica do provedor: mulheres, trabalho e história do trabalho. Mundos do Trabalho, Florianópolis, v. 1, n. 2, p. 147-170, 2009.

15 SILVA, Maciel Henrique Carneiro da. De ruas estreitas e outros espaços: as domésticas de Recife e Salvador (1870-1910). Mundos do Trabalho, Florianópolis, v. 3, n. 5, p. 58-85, 2011; SOUZA, Flavia Fernandes de. Trabalho doméstico: considerações sobre um tema recente de estudos na História do Social do Trabalho no Brasil. Mundos do Trabalho, Florianópolis, v. 7, n. 13, p. 275-296, 2015. 
Leão de Aquino Barreto, Natália Batista Peçanha, Gabriela Mitidieri e Tatiana Silva de Lima. O dossiê é fechado com uma longa entrevista de Nair Jane de Castro Lima, liderança histórica das trabalhadoras domésticas do Rio de Janeiro, concedida a Paulo Fontes, Louisa Acciari, Tatiane de Oliveira Pinto e Yasmin Getirana Gonçalves Vicente. Trata-se de um amplo painel sobre o assunto, tanto do ponto de vista temático, quanto cronológico e espacial. ${ }^{16}$

A agência dos trabalhadores das cidades e do campo em face da legislação trabalhista e da Justiça do Trabalho foi estudada em variadas balizas cronológicas e espaciais por Juan Manuel Palacio, Fernando Teixeira da Silva, Christine Dabat e Thomas Rogers, Antonio Torres Montenegro, Alisson Droppa e Alessandra Belo Assis Silva, publicados em diferentes números da revista nos anos de 2011, 2012, 2014 e 2019. ${ }^{17}$

As tensas relações entre indivíduo e sociedade, objeto de antigas polêmicas acadêmicas (e políticas), foram postas à prova em um dossiê intitulado "Biografia e História do Trabalho", organizado por Benito Bisso Schmidt e Aldrin Castellucci, publicado em dois números de 2016 da Mundos do Trabalho. O dossiê reuniu artigos de Alexandre Fortes e Flavia Ribeiro Veras, Elaine Pereira Rocha, César Augusto Bubolz Queirós, Maria do Socorro de Abreu e Lima e Luiz Anastácio Momesso, Matheus Cardoso Silva, Carlos Fernando Quadros, Rodrigo de Azevedo Weimer, Lucas Porto Marchesini Torres, Kauan Willian dos Santos e Cristiane Santos de Jesus. ${ }^{18}$

16 SOUZA, Flavia Fernandes de; SILVA, Maciel Henrique. Apresentação. Trabalho doméstico: sujeitos, experiências e lutas. Mundos do Trabalho, Florianópolis, v. 10, n. 20, p. 9-14, 2018; PASSANITI, Paolo. A cidadania submersa. O trabalho doméstico na Itália entre os séculos XIX e XX. Mundos do Trabalho, Florianópolis, v. 10, n. 20, p. 15-30, 2018; ROBERTS, Madeleine Octavia. De "um pé na cozinha" a "um pé na porta": a PEC das Domésticas no Brasil, suas oportunidades e seus desafios. Mundos do Trabalho, Florianópolis, v. 10, n. 20, p. 31-59, 2018; SOUSA, Juliana. O XI Congresso Nacional das Trabalhadoras Domésticas e a luta por direitos no Brasil. Mundos do Trabalho, Florianópolis, v. 10, n. 20, p. 61-80, 2018; BARRETO, Marina Leão de Aquino. Gênero e raça no trabalho doméstico livre em Salvador em fins do século XIX: o surgimento de uma classe fatalmente segmentada. Mundos do Trabalho, Florianópolis, v. 10, n. 20, p. 81-102, 2018; PEÇANHA, Natália Batista. "Precisa-se de uma menor para pequenos serviços de uma casa": a mão de obra infanto-juvenil no serviço doméstico carioca (1880-1930). Mundos do Trabalho, Florianópolis, v. 10 , n. 20 , p. 103-123, 2018; MITIDIERI, Gabriela. ¿Labores femeninas o trabajo? Mujeres dedicadas a la costura en Buenos Aires, 1852-1862. Mundos do Trabalho, Florianópolis, v. 10, n. 20, p. 125-144, 2018; LIMA, Tatiana Silva de. Trabalho escravo e trabalho livre: os libertos ocupados nos serviços domésticos no Recife oitocentista. Mundos do Trabalho, Florianópolis, v. 10, n. 20, p. 145-166, 2018; FONTES, Paulo; ACCIARI, Louisa; PINTO, Tatiane de Oliveira; VICENTE, Yasmin Getirana Gonçalves. "Eu tinha minha liberdade": Entrevista de Nair Jane de Castro Lima, liderança histórica das trabalhadoras domésticas do Rio de Janeiro. Mundos do Trabalho, Florianópolis, v. 10, n. 20, p. 167-189, 2018.

17 PALACIO, Juan Manuel. Legislación y justicia laboral en el "populismo clásico" latinoamericano: Elementos para la construcción de una agenda de investigación comparada. Mundos do Trabalho, Florianópolis, v. 3, n. 5, p. 245-265, 2011; DROPPA, Alisson. Justiça do Trabalho e as conquistas dos direitos: o direito de conhecer a história da Justiça do Trabalho. Mundos do Trabalho, Florianópolis, v. 3, n. 5, p. 43-58, 2011; SILVA, Fernando Teixeira da. "Justiça de classe": tribunais, trabalhadores rurais e memória. Mundos do Trabalho, Florianópolis, v. 4, n. 7, p. 124-160, 2012; MONTENEGRO, Antonio Torres. Direitos trabalhistas e assassinato em tempos de regime civil-militar (1972 - 1973): o indiciamento dos irmãos Barreto. Mundos do Trabalho, Florianópolis, v. 6, n. 11, p. 91-106, 2014; DABAT, Christine; ROGERS, Thomas. "Uma peculiaridade do trabalho nesta região". A voz dos trabalhadores nos arquivos da Justiça do Trabalho na Universidade Federal de Pernambuco. Mundos do Trabalho, Florianópolis, v. 6, n. 12, p. 124-160, 2014; SILVA, Alessandra Belo Assis. Trabalhadores precários no Tribunal Superior do Trabalho: salário, contrato e jornada de trabalho (Brasil, 1946-1953). Mundos do Trabalho, Florianópolis, v. 11, p. 1-31, 2019.

18 SCHMIDT, Benito Bisso; CASTELLUCCI, Aldrin. A título de apresentação: biografia e história do trabalho (I). Mundos do Trabalho, Florianópolis, v. 8, n. 15, p. 5-8, 2016; FORTES, Alexandre; VERAS, Flavia Ribeiro. No rastro de Jararaca: produção cultural e engajamento político na trajetória de um artista popular pioneiro. Mundos do Trabalho, Florianópolis, v. 8, n. 15, p. 11-28, 2016; ROCHA, Elaine Pereira. Vida de professora: ideias e aventuras de Leolinda de Figueiredo Daltro durante a Primeira República. Mundos do Trabalho, 
Aldrin Castellucci, Caio Castro Gerbelli, David P. Lacerda, Melina K. Perussatto, Micaele Irene Scheer e Nauber Gavski da Silva

Mundos do Trabalho entende trabalho e trabalhador em perspectiva ampla, não separando e isolando em campos de estudo distintos as variadas formas de trabalho compulsório (inclusive indígena), o labor e as lutas de escravos e libertos, trabalhadores assalariados e ocasionais, coolies, o trabalho doméstico etc. Já em 2014, a revista publicou um dossiê organizado por Vânia Maria Losada Moreira, Ingrid de Jong e Fabiane Popinigis sobre trabalho indígena, contando com artigos de Maria Regina Celestino de Almeida, Antonio Escobar Ohmstede, Paula Cecilia Zagalsky, Marta Irurozqui, Mariana Albuquerque Dantas, Ayalla Oliveira Silva e Claudia Salomon Tarquini, Elisabet Rollhauser e Mariano Nagy. ${ }^{19}$

Em 2017 essas e outras questões também foram retomadas no dossiê sobre "História Social do Trabalho na Amazônia", organizado por Adalberto Paz e Lara de Castro, e artigos de Rafael Ale Rocha, Luiz Carlos Laurindo Junior, Davi Avelino Leal, Francisnaldo Sousa dos Santos e Francivaldo Alves Nunes, Luís Balkar Sá Peixoto Pinheiro e Luciano Everton Costa Teles. ${ }^{20}$ Em outros números, a revista deu sequência à publicação de pesquisas sobre

Florianópolis, v. 8, n. 15, p. 29-47, 2016; QUEIRÓS, César Augusto Bubolz. O Trabalhismo de Plínio Ramos Coelho e o Golpe de 1964 no Amazonas. Mundos do Trabalho, Florianópolis, v. 8, n. 15, p. 49-65, 2016; LIMA, Maria do Socorro de Abreu e; MOMESSO, Luiz Anastácio. A trajetória de um líder comunista: Edvaldo Ratis e o Sindicato dos Gráficos. Mundos do Trabalho, Florianópolis, v. 8, n. 15, p. 67-85, 2016; SILVA, Matheus Cardoso. Victor Gollancz: um editor socialista nos anos do Popular Front britânico. Mundos do Trabalho, Florianópolis, v. 8, n. 15, p. 87-108, 2016; QUADROS, Carlos Fernando. Experiências de formação política e intelectual de um comunista: família, etnia, leituras e militância estudantil de Jacob Gorender, um jovem membro do PCB em Salvador (1923-1943). Mundos do Trabalho, Florianópolis, v. 8, n. 15, p. 109126, 2016; SCHMIDT, Benito Bisso; CASTELLUCCI, Aldrin. A título de apresentação: biografia e história do trabalho (II). Mundos do Trabalho, Florianópolis, v. 8, n. 16, p. 5-7, 2016; WEIMER, Rodrigo de Azevedo. Em que a trajetória do senhor Manoel Inácio Marques Neto pode contribuir à compreensão da formação do proletariado brasileiro? (Rio Grande do Sul, década de 50 do século XX). Mundos do Trabalho, Florianópolis, v. 8, n. 16, p. 11-32, 2016; TORRES, Lucas Porto Marchesini. Percursos e percalços do sargento Prestes de Paula: trajetória de um militar comunista em busca de entrosamento social no Brasil republicano. Mundos do Trabalho, Florianópolis, v. 8, n. 16, p. 33-56, 2016; SANTOS, Kauan Willian dos. Ultrapassando limites, conjurando a liberdade: revolução e nação na intensa trajetória política de Angelo Bandoni em São Paulo nas duas primeiras décadas do século XX. Mundos do Trabalho, Florianópolis, v. 8, n. 16, p. 57-74, 2016; JESUS, Cristiane Santos de. Em defesa da liberdade: as experiências de Lúcio José Maria de Souza na segunda metade do século XIX. Mundos do Trabalho, Florianópolis, v. 8, n. 16, p. 75-91, 2016.

19 MOREIRA, Vânia Maria Losada; JONG, Ingrid de; POPINIGIS, Fabiane. Apresentação. Trabalho, política e experiências indígenas. Mundos do Trabalho, Florianópolis, v. 6, n. 12, p. 5-8, 2014; ALMEIDA, Maria Regina Celestino de. Escravidão indígena e trabalho compulsório no Rio de Janeiro colonial. Mundos do Trabalho, Florianópolis, v. 6, n. 12, p. 11-25, 2014; OHMSTEDE, Antonio Escobar. Instituições e trabalho indígena na América espanhola. Mundos do Trabalho, Florianópolis, v. 6, n. 12, p. 27-53, 2014; ZAGALSKY, Paula Cecilia. Trabalhadores indígenas mineiros no Cerro Rico de Potosí: perseguindo os rastros de suas práticas laborais (séculos XVI e XVII). Mundos do Trabalho, Florianópolis, v. 6, n. 12, p. 55-82, 2014; IRUROZQUI, Marta. O trabalho os fará cidadãos. Tributo e armas na Bolívia do século XIX. Mundos do Trabalho, Florianópolis, v. 6, n. 12, p. 83-106, 2014; DANTAS, Mariana Albuquerque. Trabalho, território e participação indígena na Guerra dos Cabanos e na Insurreição Praieira: apoios e disputas nas aldeias de Barreiros e Jacuípe (Pernambuco e Alagoas, 1832-1848). Mundos do Trabalho, Florianópolis, v. 6, n. 12, p. 107-129, 2014; SILVA, Ayalla Oliveira. Territorialização e trabalho: atuação dos aldeados de Ferradas no processo de ocupação e exploração territorial, no sul da Bahia (século XIX). Mundos do Trabalho, Florianópolis, v. 6, n. 12, p. 131-152, 2014; TARQUINI, Claudia Salomon; ROLLHAUSER, Elisabet; NAGY, Mariano. Trabalho e trajetórias familiares de indígenas em Pampa e no oeste de Buenos Aires (Argentina, 1882-1920). Mundos do Trabalho, Florianópolis, v. 6, n. 12, p. 153-173, 2014.

20 PAZ, Adalberto e CASTRO, Lara de. Apresentação. Trabalho e trabalhadores na história da Amazônia. Mundos do Trabalho, Florianópolis, v. 9, n. 17, p. 5-9, 2017; ROCHA, Rafael Ale. Os oficiais índios e a mão de obra indígena livre na Amazônia colonial (1700-1798). Mundos do Trabalho, Florianópolis, v. 9, n. 17, p. 13-28, 2017; LAURINDO JUNIOR, Luiz Carlos. Trabalho escravo em Belém do Grão-Pará no contexto de crise da escravidão negra (1871-1888): qualificação profissional, lugares e formas de trabalho. Mundos do Trabalho, Florianópolis, v. 9, n. 17, p. 29-45, 2017; LEAL, Davi Avelino. Trabalho, territorialização e conflito pelo uso dos recursos naturais no Rio Madeira/AM (1861-1932). Mundos do Trabalho, Florianópolis, v. 9, n. 17, p. 47-61, 2017; SANTOS, Francisnaldo Sousa dos; NUNES, Francivaldo Alves. Entre estrangeiros e nacionais: agentes públicos e o ideal de trabalhador na propaganda e legislação nos primeiros anos da 
a escravidão, processos de emancipação, o pós-abolição e o destino dos trabalhadores negros e mestiços. Nesse caso, cabe mencionar os artigos de Renata Figueiredo Moraes em 2015, Melina Kleinert Perussatto em 2018 e Wellington Castellucci Junior e Virgínia Queiroz Barreto em 2019. ${ }^{21}$

Ao longo dos anos, Mundos do Trabalho realizou reflexões teóricas, conceituais e historiográficas sobre história do trabalho. Os temas e problemas de pesquisa mencionados ao longo deste texto foram objeto de balanços feitos por Marcel van der Linden e Juan Suriano, em 2009, Isabel Bilhão, em 2010, Rebecca J. Scott, Bryan D. Palmer e Mirta Zaida Lobato, em 2013, Barbara Weinstein em 2017 e Benito Bisso Schmidt e Henrique Espada Lima em 2018. ${ }^{22}$ O grande volume 12 da Mundos do Trabalho que oferecemos aos leitores em 2020 é, por tudo que foi dito, o resultado de uma longa e bem-sucedida trajetória de combates pela história social do trabalho, coroamento dos êxitos do campo de pesquisa e de sua revista no Brasil. Com efeito, a seção livre do volume, composta por 14 artigos, é aberta com um instigante texto de Ruy Gomes Braga, em inglês e português, sobre as mobilizações contemporâneas dos trabalhadores informais, pobres e precários, isto é, excluídos dos arranjos clássicos de trabalho (fordistas) do Atlântico Norte, no chamado Sul Global. ${ }^{23}$

Do Sul Global contemporâneo, o volume de 2020 viajou no tempo para buscar as experiências e a agência dos trabalhadores africanos e asiáticos em contextos de colonialismo, racismo e antirracismo nos séculos XIX e XX por meio dos densos artigos de Alex Lichtenstein sobre a África do Sul, Maria Luiza Ferreira Oliveira com foco em Moçâmedes (Angola) e Gopalan Balachandran centrado nos marinheiros indianos empregados na marinha mercante britânica. ${ }^{24}$

República no Pará. Mundos do Trabalho, Florianópolis, v. 9, n. 17, p. 63-78, 2017; PINHEIRO, Luís Balkar Sá Peixoto. Lideranças estrangeiras entre os trabalhadores manauaras (1910-1930). Mundos do Trabalho, Florianópolis, v. 9, n. 17, p. 79-100, 2017; TELES, Luciano Everton Costa. Tércio Miranda: uma liderança anarquista na Amazônia (1913-1914). Mundos do Trabalho, Florianópolis, v. 9, n. 17, p. 101-119, 2017.

21 MORAES, Renata Figueiredo. Trabalhadores e liberdade - A abolição da escravidão e as comemorações de 1888. Mundos do Trabalho, Florianópolis, v. 7, n. 13, p. 177-191, 2015; PERUSSATTO, Melina Kleinert. A trajetória de Tácito Pires entre a história social do trabalho e do pós-abolição (Rio Grande do Sul, 18741939). Mundos do Trabalho, Florianópolis, v. 10, n. 19, p. 43-58, 2018; CASTELLUCCI JUNIOR, Wellington; BARRETO, Virgínia Queiroz. Uma lei para os libertos: recrutamentos e território quilombola no Recôncavo da Bahia, 1800-1860. Mundos do Trabalho, Florianópolis, v. 11, p. 1-27, 2019.

22 LINDEN, Marcel van der. História do Trabalho: o velho, o novo e o global. Mundos do Trabalho, Florianópolis, v. 1, n. 1, p. 11-26, 2009; SURIANO, Juan. ¿Cuál es hoy la historia de los trabajadores en la Argentina? Mundos do Trabalho, Florianópolis, v. 1, n. 1, p. 27-50, 2009; BILHÃO, Isabel. A construção da identidade operária brasileira: aspectos de uma trajetória historiográfica. Mundos do Trabalho, Florianópolis, v. 2, n. 4, p. 218-234, 2010; SCOTT, Rebecca J. O trabalho escravo contemporâneo e os usos da história. Mundos do Trabalho, Florianópolis, v. 5, n. 9, p. 129-137, 2013; PALMER, Bryan D. A história enquanto debate: a análise contestadora de A Formação da Classe Operária Inglesa. Mundos do Trabalho, Florianópolis, v. 5, n. 10, p. 13-35, 2013; LOBATO, Mirta Zaida. Mi lectura de la Formación histórica de la clase obrera en Inglaterra de Edward Palmer Thompson. Mundos do Trabalho, Florianópolis, v. 5, n. 10, p. 37-51, 2013; WEINSTEIN, Barbara. Globalizando a história do trabalho: o caso da revista Internacional Labor and Working-Class History. Mundos do Trabalho, Florianópolis, v. 9, n. 18, p. 11-23, 2017; SCHMIDT, Benito Bisso. Complexificando a interseccionalidade: perspectivas queer sobre o mundo do trabalho. Mundos do Trabalho, Florianópolis, v. 10, n. 19, p. 31-41, 2018; LIMA, Henrique Espada. História global do trabalho: um olhar desde o Brasil. Mundos do Trabalho, Florianópolis, v. 10, n. 19, p. 59-70, 2018.

23 BRAGA, Ruy Gomes. A "Thompsonian" pattern of labour unrest? Social movements and rebellions in the Global South. Mundos do Trabalho, Florianópolis, v. 12, p. 1-17, 2020.

24 LICHTENSTEIN, Alex. "Sentimos que nossa força está no chão de fábrica": dualismo, poder do chão de fábrica e reforma das leis do trabalho no fim do apartheid na África do Sul. Mundos do Trabalho, Florianópolis, v. 
Aldrin Castellucci, Caio Castro Gerbelli, David P. Lacerda, Melina K. Perussatto, Micaele Irene Scheer e Nauber Gavski da Silva

$\mathrm{Na}$ sequência, a revista oferece a seus leitores quatro artigos sobre processos e condições de trabalho em diferentes épocas e regiões do Brasil. Os autores são Marcelo Mac Cord com uma alentada pesquisa sobre gênero, idade, qualificação profissional e nacionalidade em uma fábrica de chapéus do Recife na década de 1880; Lyndon de Araújo Santos analisando relações sociais, etnia, poder e gênero na Fábrica de Chapéus Mangueira entre os anos de 1920 e 1940; Vinícius de Rezende, em estudo comparativo original centrado na implantação dos métodos de produção e técnicas de gestão do sistema Bata na fabricação de calçados no Brasil e no Chile entre as décadas de 1940 e 1970; e Alessandro Filipe de Meneses Gomes em texto que examina as rivalidades entre os carroceiros e a empresa Locomotora Pernambucana pelo transporte de cargas no Recife entre 1870 e $1890 .^{25}$

O bloco de artigos sobre o associativismo dos trabalhadores é aberto pela pesquisa de Felipe Azevedo e Souza sobre as trajetórias e a atuação político-eleitoral dos trabalhadores vinculados à Liga Operária de Pernambuco. ${ }^{26} \mathrm{Em}$ seguida temos os estudos de Lívia Cintra Berdu sobre a Sociedade de Resistência dos Trabalhadores em Trapiche e Café entre 1904 e 1913. Ângela Pereira Oliveira Balladares analisou a atuação de Rodolfo Xavier (1876-1964) no associativismo e na imprensa negra, especialmente no jornal A Alvorada, publicado em Pelotas, Rio Grande do Sul, entre 1907 e 1965. No mesmo conjunto, seguindo uma tendência da revista de romper com as fronteiras entre campo e cidade e abarcar tanto trabalhadores urbanos quanto rurais, publicamos o artigo de Márcio Ananias Ferreira Vilela e Arthur Victor Barros acerca da Liga Camponesa de Goiana, município da Zona da Mata Norte de Pernambuco, entre os anos finais da década de 1950 e início dos anos 1960.27

Reiterando sua prática de integrar os estudos sobre trabalhadores sob diferentes status jurídicos e sociais, diversos tipos de contrato e variados arranjos de trabalho, a revista publicou o artigo de Adalberto Paz a respeito do modo como autoridades públicas e agentes privados

12, p. 1-27, 2020; OLIVEIRA, Maria Luiza Ferreira. Dimensões do governo colonial em Moçâmedes e suas conexões com o Brasil: trabalho, negócios e conflitos, 1840-1860. Mundos do Trabalho, Florianópolis, v. 12, p. 1-27, 2020; BALACHANDRAN, Gopalan. Trabalhadores no mundo: marinheiros indianos, c. de 1870-1940. Mundos do Trabalho, Florianópolis, v. 12, p. 1-21, 2020.

25 CORD, Marcelo Mac. Operários e operárias da fábrica a vapor de chapéus de Antônio José Maia \& Cia.: gênero, idade, qualificação profissional e nacionalidade. Recife, década de 1880. Mundos do Trabalho, Florianópolis, v. 12, p. 1-31, 2020; SANTOS, Lyndon de Araújo. O mundo do trabalho carioca: chapeleiras e chapeleiros na Fábrica de Chapéus Mangueira (1920-1940). Mundos do Trabalho, Florianópolis, v. 12, p. 1-22, 2020; REZENDE, Vinícius de. Totalitarismo empresarial: uma análise do sistema Bata no Brasil e no Chile (1940-1970). Mundos do Trabalho, Florianópolis, v. 12, p. 1-33, 2020; GOMES, Alessandro Filipe de Meneses. Os carroceiros do Recife (1870-1890): organização, insubordinação e relações de poder. Mundos do Trabalho, Florianópolis, v. 12, p. 1-18, 2020.

26 SOUZA, Felipe Azevedo. A blusa e a urna: metamorfoses do associativismo de trabalhadores em Pernambuco entre o Império e a República. Mundos do Trabalho, Florianópolis, v. 12, p. 1-18, 2020.

27 BERDU, Lívia Cintra. A Sociedade de Resistência dos Trabalhadores em Trapiche e Café: novos questionamentos para incontornáveis debates (1904-1913). Mundos do Trabalho, Florianópolis, v. 12, p. 1-20, 2020; BALLADARES, Ângela Pereira Oliveira. Notas a respeito de homens negros nas narrativas de Rodolfo Xavier para o jornal A Alvorada (Pelotas, Pós-abolição). Mundos do Trabalho, Florianópolis, v. 12, p. 1-28, 2020; VILELA, Márcio Ananias Ferreira; BARROS, Arthur Victor. Trabalhadores rurais e o "credo vermelho": experiências protestantes na Liga Camponesa em Goiana, Pernambuco. Mundos do Trabalho, Florianópolis, v. 12, p. 1-18, 2020. 
articularam formas legais de impelir os pobres livres e libertos ao trabalho em serviços e obras públicas e particulares na Amazônia entre 1775 e $1859 .{ }^{28}$

A seção livre é fechada com artigos de César Augusto Bubolz Queirós sobre o surgimento e consolidação das lideranças políticas do Partido Trabalhista Brasileiro (PTB) no Amazonas entre 1945 e 1964; Richard Kennedy Nascimento Candido a respeito da participação feminina nas comemorações do Primeiro de Maio em Manaus na década de 1910; e Fabiana Ribeiro de Andrade Junqueira revisitando o tema das greves gerais de 1917 e 1919 a partir de um lócus diferenciado: a cidade de Piracicaba, no interior do estado de São Paulo. ${ }^{29}$

O volume 12 (2020) da Mundos do Trabalho trouxe dois dossiês de dimensões extraordinárias. O primeiro a ser publicado foi o intitulado "Os mundos do trabalho e suas interfaces com a ciência, a saúde e a doença", organizado por Gabriela dos Reis Sampaio e Ricardo dos Santos Batista e composto por um total de 18 textos, sendo uma apresentação dos organizadores, uma entrevista com Sidney Chalhoub e artigos de Maria-Isabel Porras-Gallo; Christiane Maria Cruz de Souza; Alexandra Patrícia Esteves e Sílvia Pinto; Adrián Carbonetti e María Dolores Rivero; Liane Maria Bertucci; lamara da Silva Viana, Flávio Gomes e Tânia Salgado Pimenta; Paulo Roberto Staudt Moreira e Nikelen Acosta Witter; Alan Costa Cerqueira e Maihara Raianne Marques Vitoria; Rafael Rosa da Rocha; Ricardo dos Santos Batista; Luiz Otávio Ferreira; Pablo Maddalena; Bruno Mandelli; Claudio Bertolli Filho; Anna Beatriz de Sá Almeida e Ana Carolina de Azevedo Guedes; e André Mota. ${ }^{30}$

28 PAZ, Adalberto. Classe, cor e etnia nas legislações de compulsão ao trabalho na Amazônia: do Diretório ao fim dos Corpos de Trabalhadores (1755-1859). Mundos do Trabalho, Florianópolis, v. 12, p. 1-28, 2020.

29 QUEIRÓS, César Augusto Bubolz. A experiência democrática no Amazonas: a formação do PTB e a consolidação do Trabalhismo (1945/1964). Mundos do Trabalho, Florianópolis, v. 12, p. 1-23, 2020; CANDIDO, Richard Kennedy Nascimento. "Também eram exploradas!": as mulheres e o Primeiro de Maio em Manaus na década de 1910. Mundos do Trabalho, Florianópolis, v. 12, p. 1-22, 2020; JUNQUEIRA, Fabiana Ribeiro de Andrade. O movimento operário no interior paulista: uma análise das greves gerais de 1917 e 1919 em Piracicaba. Mundos do Trabalho, Florianópolis, v. 12, p. 1-21, 2020.

30 SAMPAIO, Gabriela dos Reis; BATISTA, Ricardo dos Santos. Tempos de covid-19: as doenças têm história, os trabalhadores também. Mundos do Trabalho, Florianópolis, v. 12, p. 1-6, 2020; SAMPAIO, Gabriela dos Reis; BATISTA, Ricardo dos Santos. Epidemias no Brasil, covid-19 e uma "distopia neoliberal". Mundos do Trabalho, Florianópolis, v. 12, p. 1-10, 2020; PORRAS-GALLO, Maria-Isabel. La Gripe de 1918-1919 y la transformación del ámbito laboral de las profesiones sanitarias en España. Mundos do Trabalho, Florianópolis, v. 12, p. 1-20, 2020; SOUZA, Christiane Maria Cruz de. A ceifa da gripe espanhola entre os trabalhadores pobres e os miseráveis da Bahia (1918-1919). Mundos do Trabalho, Florianópolis, v. 12, p. 1-28, 2020; ESTEVES, Alexandra Patrícia; PINTO, Sílvia. A gripe espanhola em Portugal: a construção da memória. O trabalho médico e a assistência hospitalar. Mundos do Trabalho, Florianópolis, v. 12, p. 1-15, 2020; CARBONETTI, Adrián; RIVERO, María Dolores. Gripe española y dinámicas laborales en la Argentina de principios del siglo XX. Mundos do Trabalho, Florianópolis, v. 12, p. 1-17, 2020; BERTUCCI, Liane Maria. A casa do trabalhador em tempos epidêmicos. São Paulo, primeiras décadas republicanas. Mundos do Trabalho, Florianópolis, v. 12, p. 1-28, 2020; VIANA, lamara da Silva; GOMES, Flávio; PIMENTA, Tânia Salgado. Doenças do trabalho: africanos, enfermidades e médicos nas plantations, sudeste escravista (aproximações). Mundos do Trabalho, Florianópolis, v. 12, p. 1-16, 2020; MOREIRA, Paulo Roberto Staudt; WITTER, Nikelen Acosta. "Costuma fornecer a diversas pessoas drogas abortivas": o ofício das parteiras, disputas profissionais e sociabilidades femininas (Porto Alegre, RS, Primeira República). Mundos do Trabalho, Florianópolis, v. 12, p. 1-22, 2020; CERQUEIRA, Alan Costa; VITORIA, Maihara Raianne Marques. "Um mal necessário?": as amas de leite e o discurso médico-higienista nas últimas décadas do século XIX. Mundos do Trabalho, Florianópolis, v. 12, p. 1-16, 2020; ROCHA, Rafael Rosa da. Liberdade profissional e exercício ilegal da medicina: o caso do curador Eduardo Silva. Mundos do Trabalho, Florianópolis, v. 12, p. 1-19, 2020; BATISTA, Ricardo dos Santos. Serviço de Higiene Industrial: trabalho, saúde e doença na Reforma Sanitária da Bahia (1925-1930). Mundos do Trabalho, Florianópolis, v. 12, p. 1-25, 2020; FERREIRA, Luiz Otávio. As guardiãs da saúde: representações e características socioculturais de enfermeiras domésticas do Rio de Janeiro, 1880-1910. Mundos do Trabalho, Florianópolis, v. 12, p. 1-17, 2020; MADDALENA, Pablo. Legislar con lo nuestro, reglamentar a la luz de la 
Aldrin Castellucci, Caio Castro Gerbelli, David P. Lacerda, Melina K. Perussatto, Micaele Irene Scheer e Nauber Gavski da Silva

O segundo dossiê de 2020 foi dedicado aos "Trabalhadores de construção: por estradas, ferrovias, açudes e outras obras"; foi organizado por Robério S. Souza e Tyrone Cândido e reuniu 10 textos, consistindo em uma apresentação e artigos de Florencia D' Uva; Tyrone Apollo Pontes Cândido; lacy Maia Mata e Robério Santos Souza; Yuri Simonini; Renata Felipe Monteiro; Luciano de Moura Guimarães; Lara de Castro; Renata Silva Gusmão; e Nathalia Capellini. ${ }^{31}$ Por fim, o volume 12 é fechado com resenhas de Paulo Santos Silva, Victor Pastore, Clarice Gontarski Speranza, Francisco Barbosa Macedo e Marlos Vinícius Gama de Matos. ${ }^{32}$

Mundos do Trabalho destaca a importância fundamental de sua parceria com o Programa de Pós-Graduação em História da Universidade do Estado da Bahia (UNEB) para o sucesso da publicação e reitera seus mais sinceros agradecimentos à Universidade Federal de Santa Catarina (UFSC) por hospedar nossa revista em seu Portal de Periódicos desde 2009.

Desejamos a todos uma excelente leitura!

OIT: los riesgos laborales en Argentina (1915-1936). Mundos do Trabalho, Florianópolis, v. 12, p. 1-18, 2020; MANDELLI, Bruno. As doenças dos mineiros de carvão do sul do Brasil em meados do século XX. Mundos do Trabalho, Florianópolis, v. 12, p. 1-23, 2020; BERTOLLI FILHO, Claudio. Sob o signo da degeneração: os "loucos-tísicos". Mundos do Trabalho, Florianópolis, v. 12, p. 1-14, 2020; ALMEIDA, Anna Beatriz de Sá; GUEDES, Ana Carolina de Azevedo. Por que não posso "querer fixar o sol e observar a lua"?: "Desviantes" do trabalho e seu adoecimento na Colônia Juliano Moreira-RJ (1930-1945). Mundos do Trabalho, Florianópolis, v. 12, p. 1-22, 2020; MOTA, André. As doenças do progresso na cidade de São Paulo: o caso das doenças cardiorrespiratórias, 1940-1970. Mundos do Trabalho, Florianópolis, v. 12, p. 1-25, 2020.

31 SOUZA, Robério S.; CÂNDIDO, Tyrone. Mundos da construção: experiências, organização e lutas. Mundos do Trabalho, Florianópolis, v. 12, p. 1-5, 2020; D' UVA, Florencia. Los trabajadores de Vía y Obras en los ferrocarriles de la Argentina a comienzos del siglo XX. Condiciones laborales, experiencias y vida cotidiana en el campamento. Mundos do Trabalho, Florianópolis, v. 12, p. 1-24, 2020; CÂNDIDO, Tyrone Apollo Pontes. Uma "revolução" dos retirantes: a greve dos operários da Estrada de Ferro de Baturité na seca de 1888. Mundos do Trabalho, Florianópolis, v. 12, p. 1-15, 2020; MATA, lacy Maia; SOUZA, Robério Santos. Protesto, insubordinação e reminiscências da escravidão na construção da ferrovia Bahia-Minas na década da abolição. Mundos do Trabalho, Florianópolis, v. 12, p. 1-19, 2020; SIMONINI, Yuri. Porto das Secas: os anônimos trabalhadores do porto de Natal (1861-1932). Mundos do Trabalho, Florianópolis, v. 12, p. 1-19, 2020; MONTEIRO, Renata Felipe. Um monumento ao sertão? Expectativas diversas em torno da construção do açude Cedro, em Quixadá-CE (1884-1906). Mundos do Trabalho, Florianópolis, v. 12, p. 1-16, 2020; GUIMARÃES, Luciano de Moura. Pela lei e contra a lei: lutas e organização dos trabalhadores da construção civil de Salvador (1919-1922). Mundos do Trabalho, Florianópolis, v. 12, p. 1-19, 2020; CASTRO, Lara de. Jornadas da fome: a rotina degradante dos trabalhadores-cassacos nas obras públicas durante as secas (Ceará, anos 1950). Mundos do Trabalho, Florianópolis, v. 12, p. 1-26, 2020; GUSMÃO, Renata Silva. Trabalhadores, obras públicas e Justiça do Trabalho no "milagre econômico" em Alagoas. Mundos do Trabalho, Florianópolis, v. 12, p. 1-20, 2020; OLIVEIRA, Nathalia Capellin Carvalho de. Cidade-empresa e controle da mão de obra na construção da usina hidrelétrica de Tucuruí (1974-1984). Mundos do Trabalho, Florianópolis, v. 12, p. 1-25, 2020.

32 SILVA, Paulo Santos. O "verdadeiro" Marx como desafio biográfico. Mundos do Trabalho, Florianópolis, v. 12, p. 1-8, 2020; PASTORE, Victor. Resgatando a classe sob as lentes do materialismo histórico. Mundos do Trabalho, Florianópolis, v. 12, p. 1-5, 2020; SPERANZA, Clarice Gontarski. Como culpar os trabalhadores por suas próprias mortes: uma análise das políticas públicas para os acidentes de trabalho durante a ditadura militar. Mundos do Trabalho, Florianópolis, v. 12, p. 1-4, 2020; MACEDO, Francisco Barbosa. A questão financeira é uma questão política. Mundos do Trabalho, Florianópolis, v. 12, p. 1-3, 2020; MATOS, Marlos Vinícius Gama de. Uma cidade dos trabalhadores, mas não para os trabalhadores: o processo de urbanização da cidade de Macapá. Mundos do Trabalho, Florianópolis, v. 12, p. 1-3, 2020. 